\title{
The secondary role of UV light in swimmers melanoma genesis
}

\begin{abstract}
Background: Swimmers are known to have a higher incidence of cutaneous melanoma. Experimental studies are unable to explain the role of ultraviolet radiation (UV) as the sole factor in swimmers cutaneous melanomas. Other mechanisms, such as the prevalence of the decomposition of Hydrogen Peroxide $\left(\mathrm{H}_{2} \mathrm{O}_{2}\right)$ in the hair follicles has been hypothesized by several authors as another etiological factor. For example, the $\mathrm{H}_{2} \mathrm{O}_{2}$ generated by keratinocytes diffuses into melanocytes and may play an important role in the etiology and pathogenesis of cutaneous melanoma. Other in vitro experiments document that in water submerged hairs, sites such as the infundibulum and at wounded hair follicles is where exogenous $\mathrm{H}_{2} \mathrm{O}_{2}$ could penetrate. The energy released during the decomposition of $\mathrm{H}_{2} \mathrm{O}_{2}$ by catalase in the eukaryotic cell was also hypothesized to be an additional factor for the origin of cancer. Epidemiological studies attribute the low incidence of Melanoma genesis in countries such as Japan to the beneficial effect of the consumption of the seaweed, Sargasum filipendula, which has antiproliferative and antioxidant properties. This manuscript supports $\mathrm{H}_{2} \mathrm{O}_{2}$ as being the missing attributable risk in swimmers cutaneous melanomas.
\end{abstract}

Methods: A literature survey was performed, which aimed to identify exogenous $\mathrm{H}_{2} \mathrm{O}_{2}$ as a key factor in the causation in cutaneous swimmers Melanoma genesis.

Results: In Swimmers, all published theories as well as actual in vitro experiments identify $\mathrm{H}_{2} \mathrm{O}_{2}$ as essential factors for cutaneous melanoma. In water-submerged hairs, there are two sites where exogenous $\mathrm{H}_{2} \mathrm{O}_{2}$ can penetrate the human hair follicle: At the hair shaft/skin junction, and sites where injury has damaged the external follicular wall.

Conclusion: Published evidence demonstrates that the incidence of cutaneous melanomas is higher in swimmers that in the general population. $\mathrm{H}_{2} \mathrm{O}_{2}$ forms by the conversion of dissolved organic matter by the sun UV light in fresh or salt-water bodies. In Swimmers, spontaneously penetrating into the hair follicles. Melanoma tumor cells are then formed by the decomposition of $\mathrm{H}_{2} \mathrm{O}_{2}$ by catalase; and the malignant cells then spread into the surrounding tissues. The sun UV light playing a secondary role with $\mathrm{H}_{2} \mathrm{O}_{2}$ hypothesized as the primary attributable risk.

Keywords: biophysics, cancerogenesis, melanoma hair follicle, $\mathrm{H}_{2} \mathrm{O}_{2}$ decomposition, Cancer UV
Volume 3 Issue 3 - 2018

\author{
Abraham A Embi \\ Citizen Scientist, USA
}

Correspondence: Abraham A Embi, Formerly Affiliated with VA Hospital, University of Miami, 13442 SW 102 Lane, Miami, Florida, USA, 33 I86, Tel +305 505 4979, Email embi2I@att.net

Received: May 06, 2018 | Published: May 24, 2018

\section{Introduction}

Melanoma is known since the ancient times and has long troubled caregivers, primarily due to its heterogeneity. ${ }^{1}$ Swimming in fresh or salt-water are linked to increase risk for cutaneous melanomas. ${ }^{2}$ Experimental studies are unable to explain the role of ultraviolet (UV) radiation as the sole factor in Melanoma genesis. It has been hypothesized that one of the factors for melanoma tumors could be the generation of reactive oxygen species [namely Hydrogen Peroxide $\left(\mathrm{H}_{2} \mathrm{O}_{2}\right)$ ] by melanin "may play an important role in the etiology and pathogenesis of cutaneous melanoma".3,4

\section{$\mathrm{H}_{2} \mathrm{O}_{2}$ from keratinocytes penetrates melanocytes}

Published reports identify keratinocytes as the main source of $\mathrm{H}_{2} \mathrm{O}_{2}$ penetrating melanocytes. "Basal hydrogen peroxide $\left(\mathrm{H}_{2} \mathrm{O}_{2}\right)$ levels in normal human epidermal keratinocytes (NHEK) and melanocytes (mel) were compared on a per cell basis and found to be significantly higher in keratinocyte. Because the ratio of keratinocytes to mel in skin is $36: 1$, keratinocytes may act as a source of reactive oxygen species (ROS) even by passive diffusion and, thus, affect melanocytic functions". ${ }^{5}$ Melanin has been described as a photo protective factor in the skin; ${ }^{6}$ it could also act as double edge sword. How? Melanin besides functioning as a broadband $\mathrm{UV}$ absorbent is a reservoir of toxic $\mathrm{H}_{2} \mathrm{O}$. In addition, experiments have documented the infundibulum (Figure 1) (Figure 2) \& Video recording and the wounded follicles (Figure 3) \& Video recording) as sites where exogenous $\mathrm{H}_{2} \mathrm{O}_{2}$ penetrates the water immersed hair follicles; and is the region where melanoma tumor cells have been previously reported to form. ${ }^{7,8}$

\section{Additional experiments supporting $\mathrm{H}_{2} \mathrm{O}_{2}$ as "missing attributably risk"}

Besides the above-mentioned molecular factors, a biophysical hypothesis was proposed linking energy derived from the decomposition of $\mathrm{H}_{2} \mathrm{O}_{2}$ by catalase in eukaryotic cells to be an additional factor for the origin of cancer. ${ }^{9}$ 


\section{Worldwide epidemiological reports, antioxidant diet and melanoma}

Circumstantial evidence attributes the low incidence of Melanoma genesis in Japan to the beneficial effect of the consumption of the brown seaweed, Sargasum filipendula. Polysaccharides from Sargasum filipendula were found to have antiproliferative and antioxidant properties. ${ }^{10,11}$

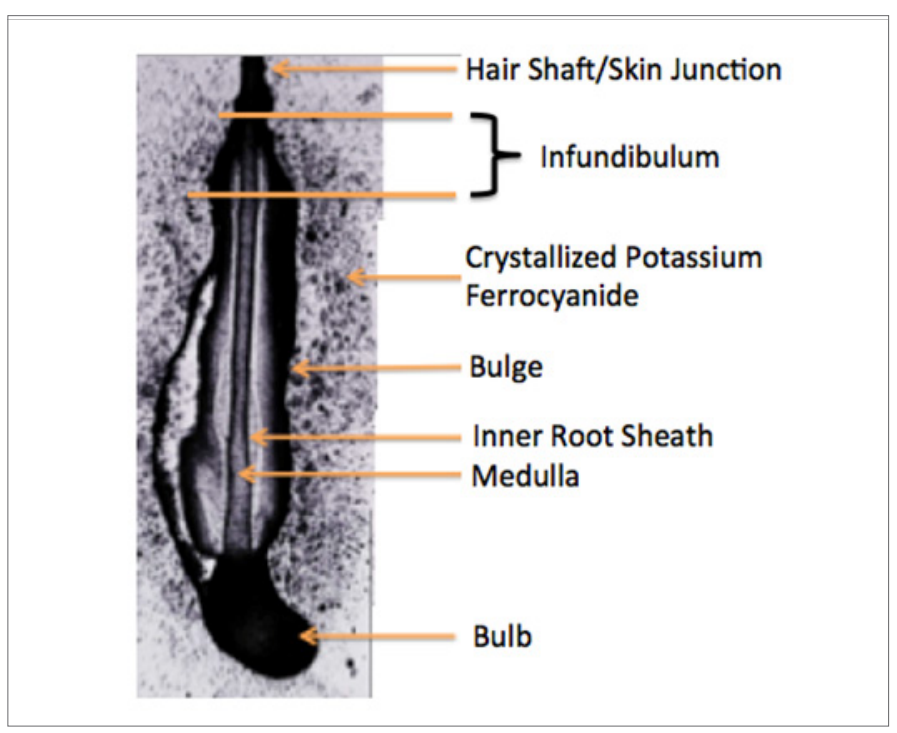

Figure I Intact plucked scalp hair immersed in Prussian Blue Stain+nano sized iron particles, Microphotograph after evaporation showing hair inner structures, Infundibulum highlighted by dark brackets.

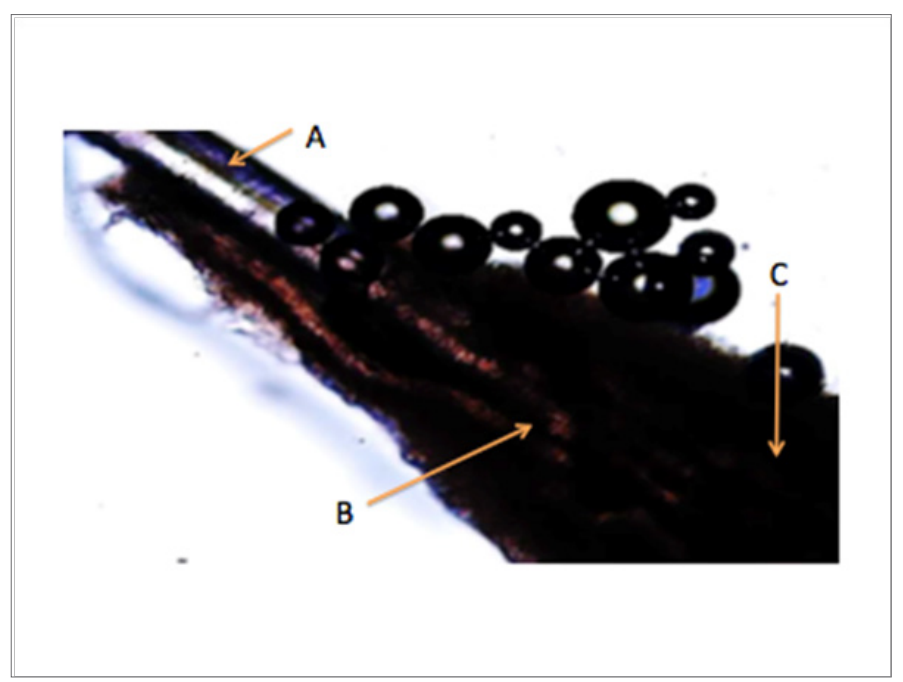

Figure 2 Unpublished microphotograph of video frame. $\mathrm{H}_{2} \mathrm{O}_{2}$ molecules spontaneously decomposed by catalase at the hair shaft/skin junction penetrating the infundibulum.

A, Hair Shaft; B, Oxygen Bubbles from $\mathrm{H}_{2} \mathrm{O}_{2}$ decomposition by catalase; $\mathrm{C}$, Hair Follicle Infundibulum.

\section{Methods}

A literature survey was conducted, which demonstrated that the carcinogenic $\mathrm{H}_{2} \mathrm{O}_{2}$ molecules penetrate the hair follicle at the junction of the skin and hair shaft at the infundibulum, and through the injured external wall.

\section{Results}

\section{Sites of melanoma genesis in hair follicles}

Published literature supports the fact that hair follicles are anatomical sites where the melanoma tumor cells are formed. As shown in Figure 1 \& Figure 2, the spontaneous penetration of exogenous $\mathrm{H}_{2} \mathrm{O}_{2}$ molecules only occurs through the infundibulum of the hair follicles. Injuries to the outer wall of hair follicles induce the penetration of $\mathrm{H}_{2} \mathrm{O}_{2}$ molecules into the follicle (Figure 3). This observation was consistent and was confirmed by a study, which reported "Water $\mathrm{H}_{2} \mathrm{O}_{2}$ Levels as factor in swimmers melanoma". ${ }^{12}$

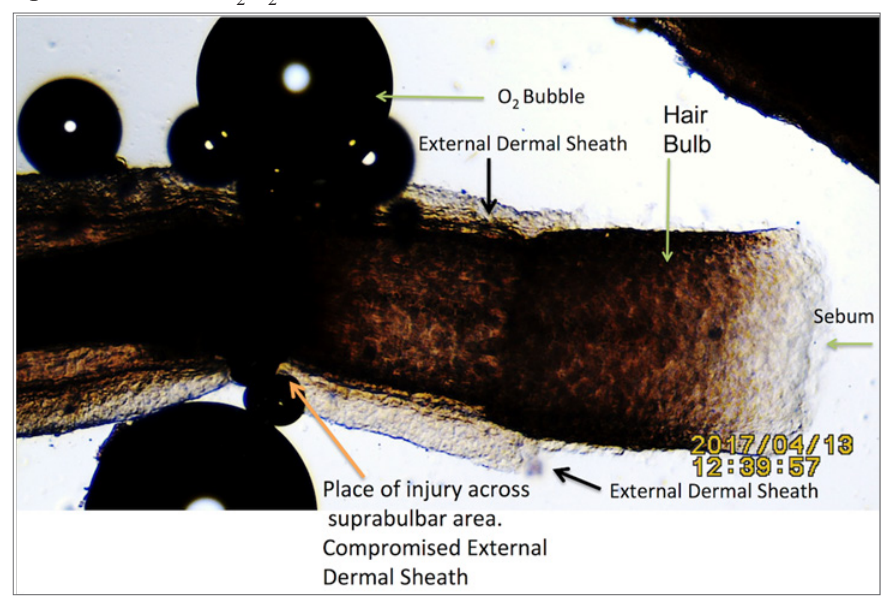

Figure 3 Injured hair follicle at mid bulb area showing place of $\mathrm{O}_{2}$ bubbles origin. Hair immersed in pure water adjacent to drops of $35 \% \mathrm{H}_{2} \mathrm{O}_{2}$. Black Arrows: External Dermal Sheath (EDS). Notice the absence of oxygen bubbles in areas protected by the EDS and sebum.

\section{Discussion}

\section{The decomposition of $\mathrm{H}_{2} \mathrm{O}_{2}$ as key factor in melanoma genesis}

A novel paradigm was hypothesized by recent experiments that demonstrated the elevation of ROS due to melanin, which served as a redox generator, for which the authors stated that, "this may play an important role in the etiology and pathogenesis of cutaneous melanoma". In another recent experiment that mimicked the Swimmers' water environment, $\mathrm{H}_{2} \mathrm{O}_{2}$ was also identified as penetrating the infundibulum of the hair follicles. In both cases, $\mathrm{H}_{2} \mathrm{O}_{2}$ was identified as a possible cause for the formation of melanoma tumors in the hair follicle. The evidences justify the role of $\mathrm{H}_{2} \mathrm{O}_{2}$ molecules as the elusive attributable risk in swimmers melanoma, ${ }^{3}$ UV radiation playing a secondary role, since its primary role only concerns the conversion of the dissolved organic matter present in water into $\mathrm{H}_{2} \mathrm{O}_{2}$ molecules, as shown in the panel below (Figure 4). ${ }^{13}$ 
Sun UV Light as Supporting Role in Swimmers Melanoma

UV radiation as a factor affecting the formation of $\mathrm{H}_{2} \mathrm{O}_{2}$ in fresh and salt-waters

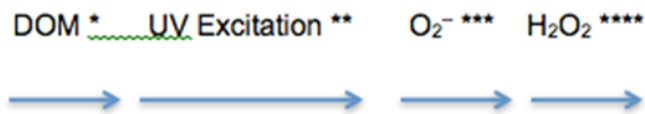

Figure 4 The sun UV radiation converts dissolved organic matters into $\mathrm{H}_{2} \mathrm{O}_{2}$. The process is shown in this figure where: DOM, Dissolved organic matter.

UV Excitation, The portion of UV radiation in sunlight (limited to the depths to which the UV radiation reaches the water body); O2, The portion of the UV radiation which leads to the formation of superoxide ions, which reacts with itself to form $\mathrm{H}_{2} \mathrm{O}_{2}$;. **** $\mathrm{H}_{2} \mathrm{O}_{2}$, The vertical distribution of hydrogen peroxide molecules present in the water body.

\section{Conclusion}

\section{Etiology of swimmers melanoma genesis}

Based on the evidences found in recent experiments and published literature, it is hypothesized that melanoma tumor cells originate and spread primarily from the hair follicles, resulting from the decomposition of $\mathrm{H}_{2} \mathrm{O}_{2}$ by catalase. The role of UV light being secondary.

\section{Further Research is warranted}

This author recommends for experimentations on skin for the animals of choice to be pig or mice, since their skin and hair follicles mimic those of humans. ${ }^{14}$ Experiments performed in pigs demonstrate that "Melanocytic cutaneous proliferation (melanomas) appeared to begin in the hair follicle and then spread into surrounding connective tissue, sweat glands, sub dermal connective tissue and fat", which raises a few questions. The first question that arises is: Would the topical application of antioxidants in pig inhibit the generation of melanoma or affect tumor regression? This question arises since pigs cool their temperature and protect their skin by bathing in mud. Dermatological studies supports and justifies the topical application of antioxidants to reduce dermatological lesions. The topical application of antioxidants is rationalized so as to avoid generating systemic imbalances of ROS and enzymatic systems. The study reports, "In situations where this balance is broken, various cellular structures, such as the cell membrane, nuclear or mitochondrial DNA may suffer structural modifications, triggering or worsening skin diseases". ${ }^{16}$ The second question that arises is, in the paper published in PNAS by Wong Could the prevalence of $\mathrm{H}_{2} \mathrm{O}_{2}$ molecules at the site of injury be ruled out in Melanomagenesis? ${ }^{17} \mathrm{~A}$ negative answer is supported by experiments where "Once a skin wound occurs, based on an experiment performed on zebra fish by mechanically injuring its tail fin, a sustained rise in $\mathrm{H}_{2} \mathrm{O}_{2}$ concentration was detected at the wound margin immediately after the injury occurred". ${ }^{4}$ For the sake of a hypothetical inquiry, supposing that the in vivo experiments in pig and mice were executed and would turn out to be successful, the results would serve as a foundation for validating $\mathrm{H}_{2} \mathrm{O}_{2}$ as the elusive attributable risk in Melanoma genesis. The role of UV light would remain as secondary.

\section{Acknowledgements}

None.

\section{Conflict of interest}

None.

\section{References}

1. Rebecca VW, Sondak VK, Smalley KS. A brief history of melanoma: from mummies to mutations. Melanoma Res. 2012; 22(2):114-122.

2. Nelemans PJ, Rampen FH, Groenendal H, et al. Swimming and the risk of cutaneous melanoma. Melanoma Res. 1994;4(5):281-286.

3. Meyskens FL, Farmer PJ, Yang S, et al. New perspectives on melanoma pathogenesis and chemoprevention. Recent Results Cancer Res. 2007;174:191-195.

4. Meyskens FL, Farmer PJ, Anton Culver H. Etiologic pathogenesis of melanoma: a unifying hypothesis for the missing attributable risk. Clin Cancer Res. 2004;10(8):2581-2583.

5. Pelle E, Mammone T, Maes D, et al. Keratinocytes act as a source of reactive oxygen species by transferring hydrogen peroxide to melanocytes. J Invest Dermatol. 2005;124(4):793-797.

6. Brenner M, Hearing VJ. The protective role of melanin against UV damage in human skin. Photochem Photobiol. 2008;84(3):539-549.

7. Pozdnyakova O, Grossman J, Barbagallo B, et al. The hair follicle barrier to involvement by malignant melanoma. Cancer. 2009;115(6):12671275 .

8. Machan, Salma MD, El Shabrawi Caelen, et al. Follicular malignant melanoma: primary follicular or folliculotropic? The American Journal of Dermatopathology. 2015;37(1):15-19.

9. Embi AA. Endogenous electromagnetic forces emissions during cell respiration as additional factor in cancer origin. Cancer Cell Int. 2016;28(16):60

10. Teas J, Irhimeh MR. Melanoma and brown seaweed: an integrative hypothesis. J Appl Phycol. 2017;29(2):941-948.

11. Costa LS, Fidelis GP, Telles CB, et al. Antioxidant and antiproliferative activities of heterofucans from the seaweed Sargassum filipendula. Mar Drugs. 2011;9(6):952-966.

12. Embi AA. Water $\mathrm{H}_{2} \mathrm{O}_{2}$ Levels as Factor in Swimmers Melanoma. Let Health Biol Sci. 2018;3(1):1-4.

13. William J Cooper, Chihwen Shao, David RS Lean, et al. Factors Affecting the Distribution of $\mathrm{H} 2 \mathrm{O} 2$ in Surface Waters. Advances in Chemistry. 1994;237(12):391-422.

14. Schmook FP, Meingassner JG, Billich A. Comparison of human skin or epidermis models with human and animal skin in in vitro percutaneous absorption. Int J Pharm. 2001;215(2):51-56.

15. Bundza A, FeltmateTE. Melanocytic cutaneous lesions and melanotic regional lymph node in slaughter swine. Cancer $J$ Vet Res. 1990;54(2):301-304.

16. Addor FAS. Antioxidants in dermatology. An Bras Dermatol. 2017;92(3):356-362.

17. Wong SY, Reiter JF Wounding mobilizes hair follicle stem cells to form tumors. Proc Natl Acad Sci USA. 2011;108(10):4093-4098. 